Volume 8. No. 9, September 2020

International Journal of Emerging Trends in Engineering Research

Available Online at http://www.warse.org/IJETER/static/pdf/file/ijeter104892020.pdf

https://doi.org/10.30534/ijeter/2020/104892020

\title{
Taguchi Analysis to Optimise the Fuel Efficiency in a Public Transportation Company and Determining the Contribution of Different Parameters
}

\author{
Dr. Putta Bore Gowda ${ }^{1}$, Dr. Prabhudev ${ }^{2}$ and Dr. R.Chandrashekar ${ }^{3}$ \\ ${ }^{1}$ Department of Mechanical Engineering, Ramaiah Institute of Technology, Bangalore, pbgowda@msrit.edu. \\ ${ }^{2}$ Departmentof labour secretary, BOCW, Govt of Karnataka Bangalore, prabhudevg@ gmail.com \\ ${ }^{3}$ Former Professor, Ramaiah Institute of Technology, Bangalore, rajchandras@gmail.com
}

\begin{abstract}
Factors like type of road, age of bus, experience of driver, etc. determine the mileage derivable from a bus. The paper attempts to find the contributions of six selected parameters in determining the fuel efficiency of the bus and also to find the optimized parametric conditions for improving the fuel efficiency.

Data available from a reputed public transportation company were collected for over two years and analyzed using the Taguchi technique. It was found that the bus run $\mathrm{km}$ had the maximum impact of $34.5 \%$ on fuel efficiency, followed by the driver's age, which impacted $21.1 \%$.

It could also be concluded that while the company buses were operating at high fuel efficiencies, a further improvement of about $12 \%$ (from 5.48 to $4.9 \mathrm{~km} / \mathrm{l}$ ) was possible by optimization of the controllable parameters, which would result in cost savings in addition to reduction in pollution..
\end{abstract}

Key words : Fuel Efficiency, Taguchi Analysis, Transportation, Cost Savings, Pollution Control.

\section{INTRODUCTION}

A typical public transport corporation in India has about 5000 buses, of various types like Ashok Layland, Volvo, etc. These buses travel on different roads like National highways, State Highways, city roads, hilly roads, etc., and carry about 300,000 passengers per day on the average. The total mileage of these buses is typically $1,700,000 \mathrm{~km} / \mathrm{day}$. The average consumption of fuel is between 4.5 and $5.0 \mathrm{~km} / \mathrm{l}$. the occupancy rate ranges from 65 to $100 \%$, averaging about $85 \%$.

Various parameters like the type of road, type of bus, etc. determine the fuel efficiency of the buses. If the fuel efficiency could be improved by $1 \%$, there would be savings of about one million $\mathrm{kL}$ of diesel annually, which, at present rates would convert into cost savings of about Rs. 65 million /year for the corporation.
The study presented in this paper details the methodology adopted for improvement in fuel efficiency of a large public transport corporation without resorting to any technical

\section{SELECTION OF PARAMETERS}

There are at least 20 parameters which affect the fuel efficiency. After detailed discussions with officials of the Corporation, seven parameters were selected as having major impact on the fuel efficiency.

Other parameters like the number of stoppages, average and maximum speed of bus, wind direction and wind speed, etc. were not considered in this study.

While bus age, bus run $\mathrm{km}$, driver age, and season were parameters considered at three levels, bus type, road type, and driver experience were considered at two levels. Table 1 below details the parameters and levels considered.

Table 1: Parameters and levels

\begin{tabular}{|c|c|c|c|}
\hline Parameter & Level-1 & Level-2 & Level-3 \\
\hline Bus type & $\begin{array}{c}\text { Ashok } \\
\text { Layland }\end{array}$ & Volvo & -- \\
\hline Road type & Good & Not so Good & -- \\
\hline Bus age & $<3$ & $3-6$ & $6-9$ \\
\hline Bus run km & $<300,000$ & $300,000-$ & $600,000-$ \\
& & 600,000 & 900,000 \\
\hline Driver age & $<35$ & $35-45$ & $45-55$ \\
\hline Driver & $<10$ & $10-20$ & -- \\
experience & & & \\
\hline Season & Summer & Rainy & Winter \\
\hline
\end{tabular}

\section{THE TAGUCHI APPROACH}

In the past decade, the use of Taguchi method for designing experiments has gained ground, and many researchers have used this methodology successfully for various optimization situations [The method has also been employed for reverse 
Putta Bore Gowda et al., International Journal of Emerging Trends in Engineering Research, 8(9), September 2020, 5551 - 5554

optimization, i.e., where the experimental results or operational data are already available and the appropriate Taguchi Orthogonal Array are fitted to the available data to determine the optimized conditions.

This methodology has been successfully employed for

a) Designing of experiments conducted in the laboratory

b) Designing of experiments in field

c) Optimization of parameters from available information / data from existing systems

d) Optimization of factors from survey-based information.

From available literature, the technique of Taguchi Orthogonal Array L'18 has been employed for optimization of parameters in situations of biodiesel usage, EDM process, plastic injection molding, cutting parameters in turning, electrical discharge machining, green sand casting process, recycling of aluminum, etc [1-9]. However, use of this technique in transportation is very rare.

\subsection{Taguchi Orthogonal Array Selection}

For the combination of seven parameters with maximum three levels, the L'18 orthogonal array was found to be suitable, as given in Table 2.

Table 2: Taguchi Orthogonal Array L'18

\begin{tabular}{|l|l|l|l|l|l|l|l|}
\hline \multirow{2}{*}{ SI.No. } & \multicolumn{7}{|c|}{ Parameter } \\
\cline { 2 - 8 } & 1 & 2 & 3 & 4 & 5 & 6 & 7 \\
\hline 1 & 1 & 1 & 1 & 1 & 1 & 1 & 1 \\
\hline 2 & 1 & 1 & 2 & 2 & 2 & 2 & 2 \\
\hline 3 & 1 & 1 & 3 & 3 & 3 & 1 & 3 \\
\hline 4 & 1 & 1 & 1 & 3 & 2 & 2 & 3 \\
\hline 5 & 1 & 2 & 2 & 1 & 3 & 1 & 1 \\
\hline 6 & 1 & 2 & 3 & 2 & 1 & 2 & 2 \\
\hline 7 & 2 & 2 & 1 & 2 & 3 & 1 & 2 \\
\hline 8 & 2 & 2 & 2 & 3 & 1 & 2 & 3 \\
\hline 9 & 2 & 1 & 3 & 1 & 2 & 1 & 1 \\
\hline 10 & 2 & 1 & 1 & 2 & 1 & 2 & 1 \\
\hline 11 & 2 & 1 & 2 & 3 & 2 & 1 & 2 \\
\hline 12 & 2 & 1 & 3 & 1 & 3 & 2 & 3 \\
\hline 13 & 3 & 1 & 1 & 1 & 2 & 1 & 3 \\
\hline 14 & 3 & 2 & 2 & 2 & 3 & 2 & 1 \\
\hline 15 & 3 & 2 & 3 & 3 & 1 & 1 & 2 \\
\hline 16 & 3 & 2 & 1 & 3 & 3 & 2 & 2 \\
\hline 17 & 3 & 2 & 2 & 1 & 2 & 1 & 3 \\
\hline 18 & 3 & 2 & 3 & 2 & 1 & 2 & 1 \\
\hline
\end{tabular}

3.2 Taguchi Orthogonal Array L'18 Applied To Operational Data:

The orthogonal array [Table 4.55] applied to the actual performance data and the response thereof in terms of KMPL is shown in Table 4.56. The $\mathrm{S} / \mathrm{N}$ Ratios have also been calculated and included in Table 3.

Table 3: L'18 Orthogonal Array applied to Operational Data

\begin{tabular}{|c|c|c|c|c|c|c|c|c|}
\hline \multicolumn{7}{|c|}{ Parameter } & \multirow[b]{2}{*}{ 页承 } & \multirow[b]{2}{*}{ 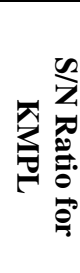 } \\
\hline 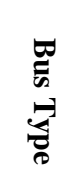 & 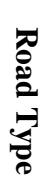 & 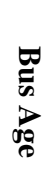 & 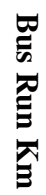 & 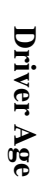 & 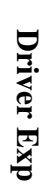 & 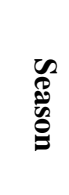 & & \\
\hline 1 & 1 & 3 & 3 & 35 & 10 & 1 & 4.41 & 1.289 \\
\hline 1 & 1 & 6 & 6 & 45 & 20 & 2 & 4.99 & 1.396 \\
\hline 1 & 1 & 9 & 9 & 55 & 10 & 3 & 4.69 & 1.342 \\
\hline 1 & 1 & 3 & 9 & 45 & 20 & 3 & 4.55 & 1.316 \\
\hline 1 & 2 & 6 & 3 & 55 & 10 & 1 & 5.05 & 1.407 \\
\hline 1 & 2 & 9 & 6 & 35 & 20 & 2 & 5.03 & 1.403 \\
\hline 1 & 2 & 3 & 6 & 55 & 10 & 2 & 5.13 & 1.420 \\
\hline 1 & 2 & 6 & 9 & 35 & 20 & 3 & 4.56 & 1.318 \\
\hline 1 & 1 & 9 & 3 & 45 & 10 & 1 & 4.80 & 1.362 \\
\hline 2 & 1 & 3 & 6 & 35 & 20 & 1 & 4.58 & 1.322 \\
\hline 2 & 1 & 6 & 9 & 45 & 10 & 2 & 4.58 & 1.322 \\
\hline 2 & 1 & 9 & 3 & 55 & 20 & 3 & 5.60 & 1.496 \\
\hline 2 & 1 & 3 & 3 & 45 & 10 & 3 & 5.29 & 1.447 \\
\hline 2 & 2 & 6 & 6 & 55 & 20 & 1 & 5.05 & 1.407 \\
\hline 2 & 2 & 9 & 9 & 35 & 10 & 2 & 4.74 & 1.352 \\
\hline 2 & 2 & 3 & 9 & 55 & 20 & 2 & 4.79 & 1.361 \\
\hline 2 & 2 & 6 & 3 & 35 & 10 & 3 & 4.99 & 1.396 \\
\hline 2 & 2 & 9 & 6 & 45 & 20 & 1 & 5.43 & 1.470 \\
\hline
\end{tabular}

The mean S/N Ratio for each level has been calculated and is summarized in Table-IV. The total mean S/N Ratio for the 18 sets was also calculated.

Table 4: Response Table for Mean S/N Ratio for KMPL

\begin{tabular}{|c|c|c|c|c|c|}
\hline 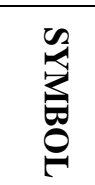 & 疍 & 窇 & 㞼 & 芴 & 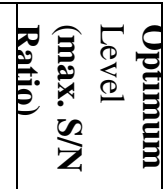 \\
\hline B & $\begin{array}{l}\text { Bus } \\
\text { Type }\end{array}$ & $\begin{array}{l}1.36153 \\
5\end{array}$ & $\begin{array}{l}1.39681 \\
8\end{array}$ & & B2 \\
\hline $\mathrm{R}$ & $\begin{array}{l}\text { Road } \\
\text { Type }\end{array}$ & $\begin{array}{l}1.36585 \\
3\end{array}$ & $\begin{array}{l}1.39249 \\
9\end{array}$ & & $\mathrm{R} 2$ \\
\hline BA & $\begin{array}{l}\text { Bus } \\
\text { Age }\end{array}$ & $\begin{array}{l}1.35907 \\
5\end{array}$ & $\begin{array}{l}1.37420 \\
5\end{array}$ & $\begin{array}{l}1.40424 \\
9\end{array}$ & BA-3 \\
\hline BKM & $\begin{array}{l}\text { Bus } \\
\text { Run }\end{array}$ & $\begin{array}{l}1.39957 \\
2\end{array}$ & $\begin{array}{l}1.40291 \\
4\end{array}$ & $\begin{array}{l}1.33504 \\
3\end{array}$ & BKM-2 \\
\hline
\end{tabular}


Putta Bore Gowda et al., International Journal of Emerging Trends in Engineering Research, 8(9), September 2020, 5551 - 5554

\begin{tabular}{|l|l|l|l|l|l|}
\hline & KM & & & & \\
\hline DA & $\begin{array}{l}\text { Driver } \\
\text { Age }\end{array}$ & $\begin{array}{l}1.34657 \\
2\end{array}$ & $\begin{array}{l}1.38549 \\
1\end{array}$ & $\begin{array}{l}1.40546 \\
6\end{array}$ & DA-3 \\
\hline DE & $\begin{array}{l}\text { Driver } \\
\text { Exp. }\end{array}$ & $\begin{array}{l}1.37076 \\
9\end{array}$ & $\begin{array}{l}1.38758 \\
3\end{array}$ & & DE-2 \\
\hline $\mathrm{S}$ & Season & $\begin{array}{l}1.37597 \\
6\end{array}$ & $\begin{array}{l}1.37558 \\
8\end{array}$ & $\begin{array}{l}1.38596 \\
4\end{array}$ & S-3 \\
\hline
\end{tabular}

Total Mean S/N Ratio $=1.379176 \mathrm{~dB}$. The response graph drawn using the values from the response table is shown in Figure(1).

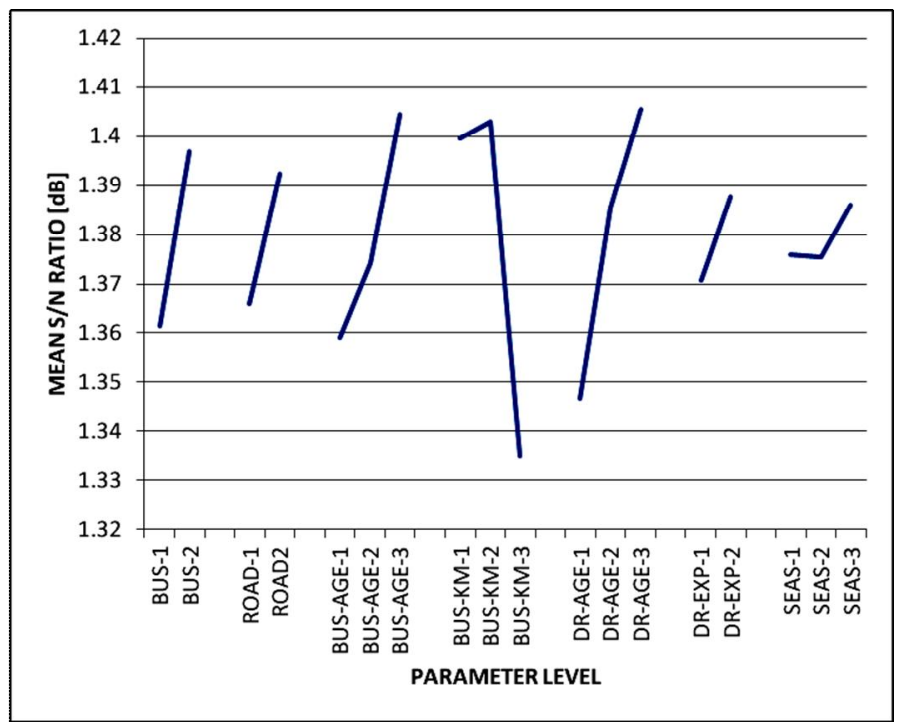

Figure 1: Response Graphs for KMPL

The optimum levels of parameters for obtaining maximum KMPL are also available in Table 4, which are: Bus type 2, Road type 2, Bus age 6-9 yrs., Bus run km 2, driver's age 45-55 yrs., driver experience 10-20 yrs., and season 3. .

\subsection{Analysis of Variance (ANOVA)}

The contributing ratio of parameters in obtaining maximum KMPL as brought out by ANOVA is shown in Table 5, and the corresponding Pareto ANOVA Diagram is shown in Figure(2).

Table 5: Results of Analysis of Variance for KMPL

\begin{tabular}{|c|c|c|c|c|c|c|}
\hline 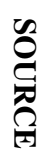 & ஜ & $\mathscr{O}$ & $\overleftrightarrow{d}$ & 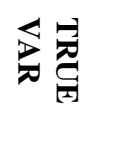 & 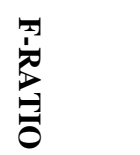 & $\begin{array}{l}\text { Oे } \\
\text { Zh } \\
\text { de }\end{array}$ \\
\hline$\underset{\sim}{\stackrel{\sigma}{二}}$ & & & & & & 73 \\
\hline & 1 & 0.001877 & 0.000934 & -0.00272 & 0.406938 & \\
\hline
\end{tabular}
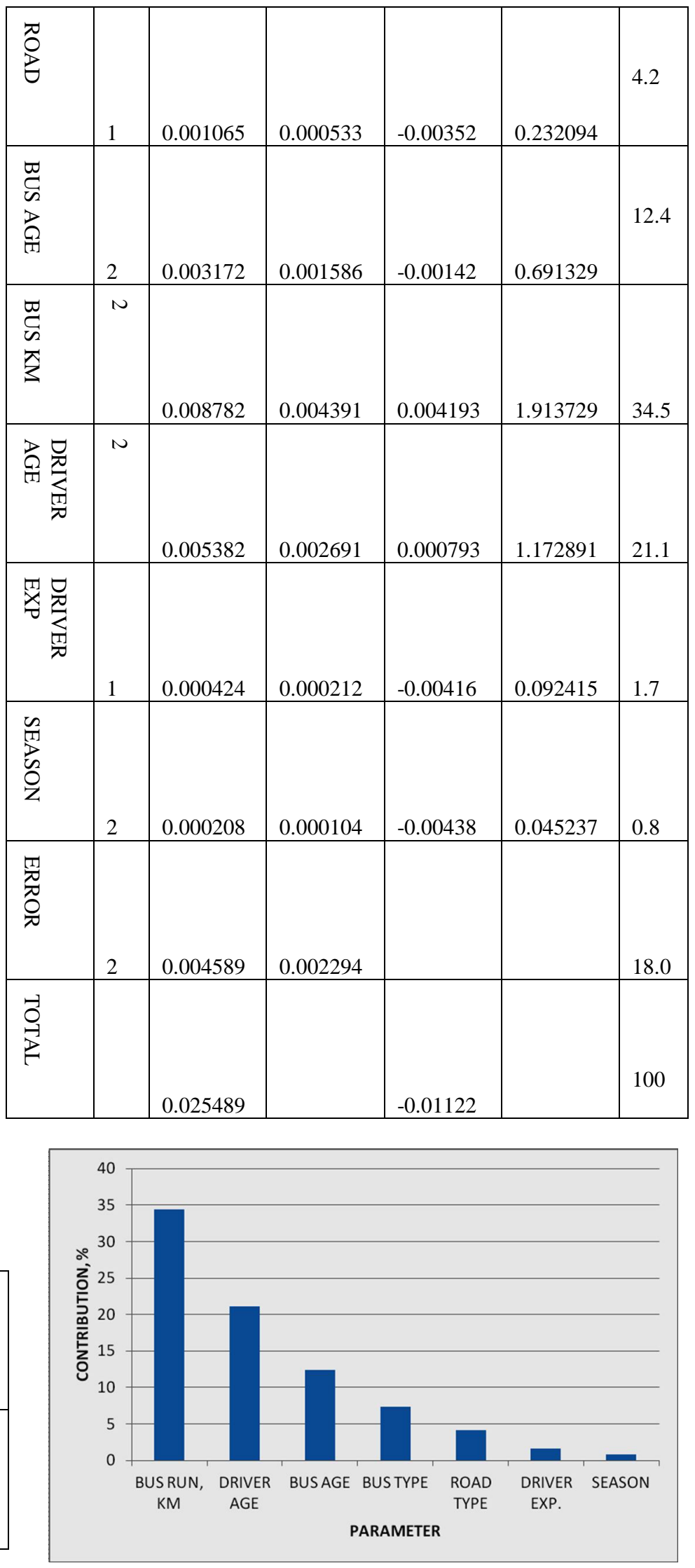

Figure 2: Pareto Analysis for KMPL 
Putta Bore Gowda et al., International Journal of Emerging Trends in Engineering Research, 8(9), September 2020, 5551 - 5554

It is seen that the effects of season, driver experience and road type on the fuel efficiency [KMPL] is low or negligible, whereas the parameters like Bus run-KM, driver age and Bus age influence the KMPL very significantly. Bus type, with a contribution of $7.3 \%$, is also not a very significant determinant parameter.

\subsection{Prediction of Optimum Performance}

At the optimum setting conditions, the optimum Fuel Efficiency [KMPL] was calculated to be $5.48 \pm 0.19 \mathrm{KMPL}$.

\subsection{Other methods for improving fuel efficiency:}

There have been many other approaches towards increasing fuel efficiency. For example Adnan et. al [11] have used ultrasonic sensors for monitoring vehicle blind spots, and Iswanto et. al[10] used additives to fuel for improving the fuel efficiency.

\section{CONCLUSION}

The Taguchi approach has resulted in the following conclusions:

1) Of the seven parameters selected as the major influencing factors in determining the fuel efficiency of a public road transport corporation, three factors were found to have significant effects, whereas the other four had insignificant effects.

2) The three parameters which had significant effects were:
a) Us Run KM - $34.5 \%$
b) Driver Age - $21.1 \%$
c) Bus Age - $12.4 \%$

The four parameters which were found to be not so significant were:
a) Bus Type - $7.3 \%$
b) Road Type - $4.2 \%$
c) Driver Experience - $1.7 \%$
d) Season - $0.8 \%$

3) If a proper combination of parameters could be selected for the operation, the fuel efficiency as measured by the $\mathrm{km}$ per liter of diesel [KMPL] would increase from the present 4.9 KMPL to 5.48 KMPL, an increase of $12 \%$. There would be a corresponding decrease in pollution from the fleet., as well as cost savings.

4) The Taguchi based approach provides an effective technique for analyzing and optimizing operational parameters in the transport industry.

\section{REFERENCES}

1. Phillip J. Ross, "Taguchi Techniques for Quality Engineering”, ISBN 0070539588, McGraw Hill Professional, 1996

2. Pridmore, A. W, A,. Bendell, J. Disney,. "Taguchi Methods: Applications in World Industry ",IFS Publications, UK, 1989.

3. Ranjit K Roy Roy, and Jean-Claude Arundhai "Design of Experiments Using the Taguchi Approach: 16 Steps to Product and Process
Improvement", ISBN-10: 0471361011, John Wiley \& Sons; Har/Cdr edition, 2001.

4. Lin, J.L., and Lin, C.L., "The use of the orthogonal array with grey relational analysis to optimize the electrical discharge machining process with multiple performance characteristics", Int. J. Machine Tools and Manufacture, 42(2), 2002, p237-244

5. Lin, J.L., and Lin, C.L., and KO, T.C. "Optimisation of the EDM Process Based on the Orthogonal Array with Fuzzy Logic and Grey Relational Analysis Method", The Internat.J. Adv. Manuf. Tech., 19(4), 2002, p271-277.

6. Antolí nG., Tinaut, F.V., Briceño', Y., Castaño,V., Pérez,C., and Ramírez, A. I., "Optimisation of biodiesel production by sunflower oil transesterification" Bio. Tech. 83(2),2002, p 111-114

7. Sushil Kumar, Satsangi, P.S., and Prajapati, D.R,. "Optimization of green sand casting process parameters of a foundry by using Taguchi's method," Int. J. Adv Manuf. Tech. 55(1), 2011, p 111-114.

8. Khoei 'A.R,. Masters, I, and Gethin, D.T,.'Design optimisation of aluminium recycling processes using Taguchi technique”, J. Matl. Proc. Tech. 127(1), 2002, p96-106.

9. Lawrence F., Rowell, Robert D., Braun, John R., Olds, and Resit Unal., "Multidisciplinary Conceptual Design Optimization of Space Transportation Systems", J.Aircraft, 36(1),1999 ,p218-226.

10. Iswanto1, Wiwik Sumarmi, Ribangun B. Jakaria, Prantasi H. Tjahjanti "The Effect of Additive on Pertalite to Increase Motorcycle Fuel Efficiency" published in IJETER Vol 8 No. 8 , Aug 2020, ISSN $2347-3983$.

11. Adnan, Z., Hassan, M. Z., Ab Wahab N, Najib, S.M, "Vehicle Blind Spot Monitoring Phenomenon using Ultrasonic Sensor" published in IJETER Vol 8 No. 8 , Aug 2020, ISSN 2347 - 3983 